\title{
Ombudsing in Higher Education: A Contingent Model for Mediation in University Dispute Resolution Processes
}

\author{
Carlos-María Alcover \\ Universidad Rey Juan Carlos (Spain)
}

\begin{abstract}
University and academia are, due to its nature, its structure and its inside relationships, a perfect breeding ground for the conflicts, disputes, problems, and grievances. In these settings, mediation is one of the dispute resolution mechanisms most used by University Ombudsperson. However, the special characteristics of university contexts make it necessary to consider and evaluate elements that may have a bearing on the effectiveness of the process and outcomes of the mediation. In this paper a model of contingent intervention in mediation processes articulated in three dimensions is put forward: a) level of balance or symmetry of power between the parties involved; b) the foreseeable temporal perspective of the relationship between them; and c) level of formalization of the mediation process. Based on the interaction between the three dimensions, a series of proposals will be formulated in order to design different strategies of intervention for mediation processes in university settings. Practical implications of this contingent model and future research on this topic are discussed.
\end{abstract}

Keywords: mediation, university ombudsman, conflict resolution, higher education

\begin{abstract}
Debido a su naturaleza, a su estructura y a las relaciones que se establecen en ellos los contextos universitarios son lugares donde surgen con frecuencia desacuerdos, problemas, conflictos y enfrentamientos. La mediación es una de las herramientas más utilizadas por los Defensores Universitarios para resolverlos. Sin embargo, las características propias de estos contextos obligan a considerar y evaluar ciertos elementos que pueden influir sobre la eficacia de los procesos y los resultados de la mediación. En este artículo se presenta un modelo contingente de mediación articulado en torno a tres dimensiones: a) nivel de simetría de poder entre las partes implicadas; b) perspectiva temporal de las relaciones entre ellas; y c) nivel de formalización del proceso de mediación. A partir de la interacción de las tres dimensiones se formula una serie de estrategias de intervención en procesos de mediación en contextos universitarios, y se discuten las implicaciones prácticas del modelo así como las futuras líneas de investigación en este ámbito.

Palabras clave: mediación, defensor universitario, resolución de conflictos, educación superior
\end{abstract}

Acknowledgements: The author would like to thank Eduardo Gamero, formerly University Ombudsman in Universidad de Huelva (Spain), and University Ombudsman since December of 2007 in the Universidad Pablo de Olavide (Seville, Spain), who was the driving force behind this work. He is also especially grateful for the valuable suggestions and feedback provided by Lourdes Munduate (Universidad de Sevilla) and Ramón Rico (Universidad Autónoma de Madrid) on a preliminary version of this paper. Finally, the author recognizes three anonymous reviewers his useful commentaries and suggestions to improve this paper.

Correspondence concerning this article should be addressed to Carlos María Alcover, University Ombudsman of Universidad Rey Juan Carlos. Departamento de Psicología, Facultad de Ciencias de la Salud. Paseo de los Artilleros s/n, 28032, Madrid (Spain). Phone: +34-914887754. E-mail: carlosmaria.alcover@urjc.es

How to cite the authors of this article: Alcover, C.M. 
Since the second half of the twentieth century and especially during the last two decades, internal dispute resolution mechanisms have become very important in all types of organizations: financial entities, health systems, prisons, universities, large corporations, and institutions (Harrison, 2004; Harrison \& Morrill, 2004). These mechanisms aim at the direct participation of the parties involved in the resolution of the conflict, complaint or other type of dispute, as well as the opportunity to express and use their voice (Hirschman, 1970) in order to change situations, demand their rights, defend their interests or call for the compliance of a norm. Among the mechanisms used for alternative dispute resolution, that avoid lawsuits, formal adjudication or the intervention of punitive actions, are mediation and ombuds dispute resolution, whose spheres of implementation have increased considerably during the last 25 years (Ambrož, 2005; Rowe, 1987, 1991; Shapiro \& Kolb, 1994; Shestowsky, 2004).

Not only is mediation one of the oldest forms of conflict resolution, but is also used worldwide (Folberg, 1983), as well as in many contexts, especially in international relations, labor-management negotiations, community disputes, school conflicts, and legal disputes (Wall, Stark, \& Standifer, 2001). More recently an important increase in the use of mediation in all types of settings and organizations has been observed: schools, families, neighbours, intercultural, law courts, etc., a tendency accompanied by the formulation of different models and approaches aimed both at research and practice (Bush \& Folger, 1994; Carnevale, 1992; Folger \& Jones, 1994; Holaday, 2002; Kressel \& Pruitt, 1989; MenkelMaedow, 1995; Picard, 2004; Winslade \& Monk, 2000).

Many human organizations, or social systems, are characterized by different types of conflict, and University is not exempt from this. Conflict in higher education takes many forms, including faculty/administration conflicts, student/faculty conflicts, scholar/faculty conflicts, intradepartment conflicts, department versus department conflicts, student/administration conflicts, and faculty/community conflicts (Doelker, 1989; Harrison, 2007). Holton (1998) identifies three sources of conflict with a special impact in university contexts: the existence of incompatible objectives, the scarcity of resources and the interferences between members.

According to Ostar (1995), conflict in universities is exacerbated not just by the fact that there are different client groups but also by the fact that each constituency claims ownership: faculty members claim in their favour the principle of academic freedom, the existence of autonomy in university management and the consideration of the university as a community of scholars; the student body demands participation in decision making processes contending that they financially support the institutions through the payment of tuition fees and due to the fact that the university would not exist without them; the administration claims its part of responsibility by virtue of its legal competences in relation to educational guidelines and policies, its financial support and its obligation to supervise the management of public funds; lastly, the support staff members also defend their right to participate in decision making based on the fact that without their contribution neither the faculty members nor the student body would be able to carry out the tasks for which they are responsible.

Since institutions of higher education are as prone to conflicts as all other human organizations, it is imperative that university practice what it purports to teach in the area of conflict resolution (Miklas \& Kleiner, 2003); and it can be good idea to practice what we preached (Doelker, 1989).

Conflict in academia contexts is handled in many ways. In recent years, the use of mediation in academia contexts has grown as a valuable and efficacy tool in resolving conflict that exists between individuals or among groups (Doelker, 1989; Miklas \& Kleiner, 2003; Stieber, 1991; Warters, 1995, 2000). In their attempts to manage these conflicts, universities have instituted formal grade appeal procedures, and many universities have established ombuds offices to provide an internal grievance mechanism for students, scholars, and administrative personnel to pursue conflicts (Bauer, 2000; Harrison, 2007; Mankin, 1996; Stieber, 1982). And the institutions try that these mechanisms are adapted to the particular characteristics of the university contexts.

Harrison and Morrill (2004) lead a study in that they verified the importance of designing dispute resolution systems adequate to achieving the stated goals of the system. And many others researches and practitioners (Kressel, 2006; Kressel \& Pruitt, 1989; Lim \& Carnevale, 1990; Ross, 2003; Rubin, 1980; Serrano \& Méndez, 1999; Wall, 1981) have acknowledge that mediators often use strategies and tactics contingent on the dispute situation, sensible to specific social and contextual constraints (LaTour, Houlden, Walker, \& Thibaut, 1976), as well as dispute resolution systems that have a high degree of flexibility (Harrison \& Morrill, 2004) and pragmatism (Wall \& Callister, 1995).

Considering together the former rationales, and specially because of the singularity and complex nature of conflict in university contexts (Doelker, 1989; Harrison, 2007; Holton, 1998; Ostar, 1995), this paper aims to present a contingent model of mediation interventions within the scope of the figure of the University Ombudsperson, based in three basic dimensions: the level of balance or symmetry of power characterizing the relationships between the parties involved; the foreseeable temporal perspective of the relationship (short-term vs. medium- and long-term); and the level of formalization of the mediation process (establishing a continuum between formal and informal mediations). In addition, the objectives of the mediations are considered as constituent elements of any process (agreement or dispute resolution and improvement of the relationship between the parties involved). 
The interactions between these dimensions will give rise to different modalities of mediation intervention in university contexts, and we postulate that the appropriateness of the choice can exercise influence on both the process and the outcome effectiveness.

\section{Ombudsing in University Settings}

\section{The University Ombudsperson}

The origins of the University Ombudsperson can be found in the United States in Eastern Montana College, where in 1966 the first ombudsperson began to work; and Michigan State University established an ombuds office in 1967 (Stieber, 1991, cf. Guerra \& Flinchbaugh, 1993; Stieber, 2000). Since then the presence of the ombudsperson has increased considerably, so that twenty years later, ombudsperson offices can be found in around 200 colleges and universities in the United States and Canada (Bloland \& Novak, 1968; Holton and Warters, 1995; Mankin 1996). And it also appears that number is growing (Harrison, 2007).

In Europe, the European Network for Ombudsmen in Higher Education (ENOHE) was created in 2003. It is an informal network for academic ombudspersons and people interested in academic ombudsing, grouping together similar figures in countries such as The Netherlands, Spain, Austria, Switzerland, Germany, United Kingdom, Belgium, and others. In Spain, although its origins go back to the mideighties when some universities voluntarily included the University Ombudsperson in their statutes, the figure of the University Ombudsperson was definitively regulated in the year 2001 with the Organic Law of Universities (LOU). This incorporation of the University Ombudsperson to the legislation confers on him/her a role with two important and closely related implications: on the one hand, it is one of the specific procedures required in the LOU to guarantee the position not only of the student body, but also all members of the university community, as an official instrument of non-jurisdictional or formal adjudication conflict resolution; on the other, to act aiming for higher quality in the university in all its spheres of activity. These broad functions situate the University Ombudsperson before many diverse issues that may, at least potentially, require his/her intervention (Espada, 2004; Gutiérrez \& Martorell, 2007; Pérez, Sánchez, \& Vila, 2004).

A university ombudsperson is an independent, impartiality and neutral person to whom students, staff, faculty and/or administrators can turn in a formal/informal and confidential manner for help with their complaints about the university and its community (Bauer, 2000; Shelton, 2000).

The University Ombudsperson does not have executive power and his/her interventions are confined to the elaboration of reports, recommendations or resolutions, which in no case can be considered administrative acts, nor are they binding or can they be appealed. The University Ombudsperson acts on request of the parties and, although there are variations in accordance with the statutes of each university, she may often also act ex-officio. The University Ombudsperson is not subjected to any imperative mandate, and acts with autonomy and independently of all university organs, though he/she normally presents and explains his activities to the university senate in an annual report for each academic year.

The problems that the University Ombudsman Office receives most frequently refer to: (a) breach of norms, (b) violation or harm of rights, (c) restriction of liberties, (d) conflicts in interpersonal and group relations, (e) interpretation of norms, (f) conflicts of interests, (g) conflicts of values, and (h) other complaints and grievances about the delays or the errors in operating diverse university services. For coping with these subjects, university ombuds strategies are predominantly communicative in nature and include such well know techniques as active listening, giving hearing to feelings, defusing rage, giving advice, creative problem solving and developing options, investigation and fact findings, shuttle diplomacy, and often mediation and coaching (Harrison, 2004; Rowe, 1987, 1991, 1995; Robbins \& Deane, 1986).

\section{A Complex Setting: Hierarchical Structure and Temporal Scope of the Relationships}

University contexts present a high degree of complexity, due to both the great diversity of activities and functions carried out and the characteristics and the interdependence relationships of its different sectors. These activities revolve around two basic functions of the university: teaching and research, which give rise to a great variety of situations, interactions and relationships involving the members of the university community, as well as generating tension upon establishing priorities between them (Freitag, 1995; Perinat, 2004). University communities are basically composed of three constituencies: students, faculty members and support staff members, not to mention the establishment of different degrees of external relations with representatives of the administration or public authorities, with members of other university organizations (local, regional, state and international) and with other social agents or stakeholders: businesses, public and private institutions, associations, professional associations, trade unions, and so forth (Barsky, 2002; Warters, 2000).

The existing interdependence among the members of the three sectors in the university community gives rise to a permanent interaction between them (Holton \& Phillips, 1995), with a horizontal character (interactions among members belonging to the same sector) and transversal (those produced between members of different sectors and including all possible combinations). University organizational structures encompass a complex mesh of horizontal and vertical elements as lines of authority, decision making, and accountability cut across colleges, faculties, departments, 
institutes, projects, and disciplines in often overlapping and conflicting manners (Hartman, 1977), and this hierarchical university structure often is a source of conflict (Barsky, 2002).

In addition, each sector is heterogeneous in regard to not only the obvious differences derived from the personal and social characteristics of its members, but also and especially to the different levels of power and status of each one of them. This strong hierarchical structure of the university community is one of its most relevant characteristics, in itself and in reference to the problems, disagreements and conflicts within it. Bing and Dye (1992) argue that hierarchical systems can be effective in organizations like the military, but they are incompatible with the nature of a university, where the purpose is to «seek and send truth». However, it is not simply a problem of hierarchical structures, but, rather as Barsky (2002) points out, one of conflicts and ambiguity in the lines of authority, communication and roles. Consequently, "rather than operate under the guise of a single institution, for instance, universities could perhaps be reconceptualized as a federation of departments, institutes, and work units. Autonomy, common goals, and interdependence would have to be negotiated in a manner similar to state-to-state relations within an international context" (Barsky, 2002, p. 173).

The different sectors of the university community show, however, some differences as to their homogeneity based on their hierarchical structure and relations of dependency, status and power. Moving from lesser to greater heterogeneity and complexity, the student body is the group with the greatest uniformity, although we may often encounter, essentially in accordance with activities of representation, differences in position: delegates of a group, class or degree; representatives in department councils, faculty or college councils, the university senate or the board of governors of the university; and, depending on the statutes of each university, members of the student body delegation or the student body council. There is also a basic distinction between undergraduate and postgraduate students. These different positions, derived from their representative functions, can bear an influence on the relationships between them, just as those established with members of the support staff and faculty members, as well as with different posts and governing bodies. Most usual conflicts in those than are involved the students are faculty-to-student conflict and student-to-student conflict (Gibson, 1995; Harrison, 2007; Miklas \& Kleiner, 2003; Warters, 1995).

As to the support staff sector, we encounter the usual differentiations in public employees in relation to their belonging to a group in accordance with their professional category, associated rank and the directors of university services, as well as those derived from a temporary consideration as position of trust. Lastly, the faculty members are classified in different groups according to the legislation in force and to their seniority and dedication. The complex and subtle informal relationships of dependence often established between them should not be overlooked, along with the personal relations and attachments inevitably produced in this type of contexts characterized by persons working in very close contact and whose temporal perspective usually goes on in time, a very important aspect that will later be referred to.

The problems, disagreements or conflicts that may occur between the members of the university community may have extremely diverse origins, and the members of the three sectors may also feel vulnerable for many reasons (Bauer, 2000). In addition, the sources of conflict may vary from university to university and reflect institution size, student population, location, governance or unionization (Volpe \& Chandler, 2001).

In short, in extremely complex realities like those that are shaped in a university organization, characterized by its openness - "conflict is inevitable in higher education, where academic freedom is revered and free thinking is encouraged" (Holton, 1995, p. 79)-, and the continuous and elevated number of interactions and relations, the existence of differences or conflicts of interests, dysfunctions and even errors must be contemplated as an element which is as inevitable as potentially positive.

Inevitable, due to the fact that human or social systems are made up of singular units that confer on them a necessarily plural character, where persons occupy different positions, and consequently carry out different roles, with different degrees of power, different interests and, in short, pursue different objectives, so that in these contexts, disagreements, conflicts, and academic grievances can be said to be natural. And potentially positive, because this differentiated structure and this diversity in its composition can -and should- lead to debate, to argumentation, to an intellectual confrontation of ideas, or to the search for reasonable solutions where there is room for the particular reasons of the actors; that is, as long as the parties involved are committed, with a constructive attitude and conviction, to reaching an understanding.

\section{Ombudsperson and Mediation in University Settings}

And this is precisely where the University Ombudsperson can help resolve the conflict, facilitating processes of mediation. It offers parties involved in conflicts and problems the opportunity to meet with one impartial, trained mediator who will support better communication and effective negotiation between them (Volpe \& Chandler, 2001). It is important for mediators and mediation interventions to acknowledge that not all conflicts can or should be mediated (Albert \& Howard, 1985). Thus, when the rights and freedom of members of the university community are seriously and flagrantly violated, or when laws, rules or obligations are failed to fulfil, the mediation is not possible. Then the University Ombudsperson should undoubtedly 
assume his or her functions of informing, pointing out the offences and recommending the strict application of the rules and regulations. Mediation is only one of the roles of Ombudsmen (Vice, 1994), and he or she cannot -and should not- expect to resolve all conflicts in this way.

Of course, mediation and other alternative dispute resolution systems have been used by many others instances for a very long time to solve conflicts in university settings; so, for example, the Consortium on Negotiation and Conflict Resolution, Georgia University (http://law.gsu.edu/CNCR/), in US context, and the consortium Improving Dispute Resolution: Transforming Policy and Practice in Dispute Resolution in Higher Education Institutions, (http://www.staffs.ac.uk/idr/index.html), founding by Higher Education Funding Council for England (HEFCE), Leeds Metropolitan University, Staffordshire University, the University of Wolverhampton, the Higher Education Mediation Service of the Oxford Centre for Higher Education Policy Studies, Martineau Johnson and the Consortium on Negotiation and Conflict Resolution, College of Law, Georgia State University, USA, in English context.

The characteristics of the mediation make it one of the tools most resorted to in ombudsperson daily work, since the absence of the executive power and structural independency inherent in his/her figure confers upon his/her fundamentally the role of facilitator in search of solutions on the part of the parties involved in the conflicts, someone who helps parties gather more information in order to overcome their misunderstandings (Rahim, 2001).

This absence of executive power and structural independency can help to the parts in conflict to perceive a priori to the University Ombudsperson like a neutral and impartial instance. But this does not mean that the Ombudsman lacks another type of influence or authority. $\mathrm{He} / \mathrm{she}$ also becomes a source of influence -essentially due to his/her personal power, as well as his/her power of position, derived not from his real authority (since he lacks coercive power) but from his/her legitimate power or moral authority related to his/her independence and neutrality, according to the classic distinction formulated by French and Raven (Raven, 1992; Raven, Schwarzwald, \& Koslowsky, 1998)-, to which the actors involved in the search for alternatives and solutions may be sensitive. Some practitioners highlight these same aspects distinguishing between the use of implicit power and explicit power (Guerra \& Elliot, 1996), whose sources, as in any process of negotiation, may be varied: information and expertise, rewards, moral authority charisma, commitment, fallback position, and so forth (Rowe, 1991).

Finally, like any other mediator, the University Ombudsman is responsible for carrying out a process with a guarantee for the parties, committed to the equality of opportunities to express opinions, ideas, suggestions and solutions and making the parties involved responsible for the content of the agreements reached (Chan, 2005; Lewicki,
Weiss \& Lewin, 1992). In addition to mediation, facilitation, and a variety of hybrid intervention efforts, Ombudspersons also provide coaching, training, and consultation services that enable individuals and groups to prevent, reduce, and intervene in conflict situations as creative problem solvers (Volpe \& Chandler, 2001).

\section{Alternatives or Modalities of University Ombudsperson's Mediation}

There is growing recognition that how mediation is practice is, in fact, very varied (Kolb, 1994; Volpe \& Chandler, 2001). An important distinction related to the types of mediation normally used by the University Ombudsperson is that established between the processes of formal and informal mediation (Volpe \& Witherspoon, 1992). The former refers to mediation carried out in accordance with a protocol or official procedure previously defined and specified, that may be encountered in the Regulations of each University Ombudsperson and is developed in the statutes of each university (and normally approved by the university senate), or, on the other hand, established ad hoc for each concrete intervention. As to the latter, they are mediation procedures that are not confined to a standardized procedure and are developed, adapting themselves to the characteristics of the situation, type of conflict and the parties involved, in accordance with the assessment and decisions of each Ombudsperson with her knowledge and experience, and where improvisation may be a key element in the management of the process as well as in the creation of scenarios that can stimulate the parties involved (Balachandra, Barrett, Bellman, Fisher, \& Susskind, 2005). The informal procedures aim to create room for confidence and security where the parties can establish a mediated dialogue using active listening which will make possible direct communication, facilitates understanding of the problem and the positions and opinions of the parties, and allows the mediator to intervene and attempt to persuade in a less institutionalized way. Like Kolb (1987) notes, "the broad guidelines of the ombudsperson's job and the novelty of this function mean that have considerable latitude to structure the forms this dispute-processing mechanism takes” (p. 673).

In a survey carried out by the author in December 2006 and January 2007, with the participation of 30 University Ombudspersons in 27 public and 3 private Spanish universities (65\% of universities that had Ombudsperson Office at that date), it was asked if their internal regulations included a formal procedure of mediation or no. Twelve of them have regulations with a formal and clearly specific procedure to carry out mediation processes in the exercise of their functions; in six cases, although a procedure is not explicitly included, the respective regulations clearly mention that mediation processes may be carried out; and in the other twelve cases, this possibility is not contemplated and a procedure is not included (Alcover, 2007). Asked if they 
used formal o informal mediation, and which considered more effective, the answers allowed to obtain important conclusions: the majority of Ombudspersons recognize that, independently of the fact that their regulations allow them or not to carry out formal mediation processes, their interventions often consist of informal mediations, and they consider that this character does not make their acts less efficient, just the opposite. For the $83 \%$ of the Spanish universities Ombudspersons, the main reason to use informal mediation strategies was the different position occupied from the parts in conflict in the university structure: to greater distance, greater informal character of the mediation. It is precisely this informal aspect which is usually highlighted as being one of the key elements of the University Ombudsperson's interventions, differentiating it from the acts of other authorities with penalizing or punitive powers, in the same way that has been verified in other contexts (Albert \& Howard, 1985). This dual character of mediation, along with others aforementioned, will be analyzed in more detail in the following section, where a proposal of a contingent model for mediation interventions in university contexts will be formulated.

\section{A Contingent Model for Ombuds Mediation in University Dispute Resolution Processes}

The contingent model is articulated around three dimensions or continuums, each referring to different aspects involved in any type of mediation. The three dimensions or continuums imply the consideration of several issues related to the characteristics of mediation process, such as (a) power relations between the parties involved, (b) temporal perspective of these relationships, and (c) formalization of the mediation process.

These dimensions do not contain all the elements characteristic of mediation processes. They are considered key factors in specialized literature, given their relevance in a specific university context to which it will be applied, as mentioned above (see, e. g., Albert \& Howard, 1985; Barsky, 2002; Doelker, 1989; Harrison, 2004, 2007; Harrison \& Morrill, 2004; Holton, 1995, 1998; Miklas \& Kleiner, 2003; Shelton, 2000; Wallace, 1993; Warters, 1995, 2000).

This model recognize that the type of mediation in resolving disputes is often contingent to the characteristics of disputes, as well as the behavior of mediators (and their strategies and tactics; see, for example, Lim \& Carnevale, 1990; Serrano \& Méndez, 1999), and sensible to social and contextual constraints (LaTour et al., 1976). In addition, the model also argues for dispute resolution systems, like mediation, that maintain a high degree of flexibility (Harrison \& Morrill, 2004) and pragmatism (Wall \& Callister, 1995) in the practice. The model shares a perspective similar to the proposal of Rooney (2007), when recommending the use of intuition in mediation; although "it still needs to be a framework within which the mediators and the parties in conflict work together, this framework, or process, should be one that gives space to allow fluid and dynamic events to take place" (p. 251).

Finally, it also aims, following the parsimony principle required by any theoretical model, to reduce the number of factors included, so as to make its practical utilization possible.

Balance or symmetry of power between the parties. Symmetry of power means that there is an identical or very similar level of power between the parties in accordance with their category, rank, position or status. Asymmetry of power means that there is a great or very significant difference in the level of power between the parties in accordance with their category, rank, position or status.

Temporal perspective of the relationship between the parties. Medium and long-term perspective means that the parties in conflict will be in close contact or pertain to departments, units, teams, services, or organizations during long time. Short-term perspective means that the character of the relationship is limited in time or when there are no expectations as to future interactions of the parties in conflict, at least in the medium or long-term.

Level of formalization of the mediation process. This last dimension or continuum refers to the basic differentiation pointed out in the previous section between formal and informal mediation processes. Formal mediation refers to an institutionalized process in accordance with official protocol or procedure (included or not in the regulations of the University Ombudsperson), known and accepted previously by the parties. Formal mediation offers the parties in conflict an opportunity to come together to analyze and to talk about their differences, and how they might handle them better in the future (Volpe \& Witherspoon, 1992). It finalizes with a written agreement accepted and signed by them, with a binding character, if not legal, at least explicit.

But it is not always possible to convene formal mediation sessions, for example when the differences between the parties are severe, deep and old, and communication and exchanges may be quick and hostile. In this context, mediator could intervene deftly and informally, and can be helpful to make some intervention on the spot. Thus, in informal mediation the mediator does not adopt the pre-established procedure in accordance with a defined framework. Instead, he/she intervenes adapting to the situation, type of conflict and the characteristics of the parties so that the latter do not feel presumably «under pressure» or «ill-at-ease» in the face of this formal or institutional process. Through informal mediation procedures mediators can either facilitate the discussion to help deescalate it or shuttle between the parties in conflict. Although informal mediation procedures on the spot can be similar to the formal sessions mentioned above, they differ significantly in that mediator generally does not have the possibility to assemble the parties, explain ground rules, and control the environment to the same extent (Volpe 
\& Witherspoon, 1992). It finalizes with a verbal agreement and the binding character of such an agreement is moral or implicit, although it is susceptible to a written agreement as in the previous modality. Upon considering it a dimension or continuum, the level of formalization of the process will include in the majority of cases a greater or lesser number of formal and informal elements; that is, generally, models that are exclusively and strictly formal or informal will not be used, but rather elements of both are present in any mediation process and their use will depend on the interaction with the elements of other dimensions.

It is necessary to consider, along with these three dimensions, a fundamental element of all conflict resolution processes: the objectives of the mediation or the effectiveness criteria. According to the concept of dyadic effectiveness (Van de Vliert, Euwema, \& Huismans, 1995; see also Munduate, Ganaza, Peiró, \& Euwema, 1999), the mediation process is considered effective insofar as (a) it allows for the resolution of the conflict and to reach an agreement, and (b) it contributes to the improvement of communication and the relationship between the parties. In university contexts, characterized, as pointed out above, by long-term relationships (which may include all or a large part of the professional life of the faculty and the support staff), it is especially important that Ombudspersons, in their role as mediators, establish the achievement of both objectives as effectiveness criteria in the process. Therefore, their mediation interventions will not only allow them to solve concrete problems, but also to contribute to the improvement of the relationship between the parties and solving for themselves the foreseeable conflicts that may arise over time, due to the characteristics of the aforementioned university contexts. In university settings, the processes of repairing and reconciling relationships are a key factor to prevent future conflicts (Harrison \& Morrill, 2004).

\section{Intervention Alternatives}

Combining the three dimensions, diverse mediation approaches or alternatives are obtained (see Figure 1).

General proposition: The utilization of the formal or informal elements of mediation are conditioned by the balance of power -symmetric or asymmetric- existing between the parties or by the temporal perspective -shortterm versus medium and long-term- of the relationship between them.

It is considered that, in the majority of cases, the mediation models that may be used include a varying combination of formal and informal elements, and only exceptionally a completely formal or informal character. What will condition the degree of the combination of both types of mediation strategies will be the balance of power

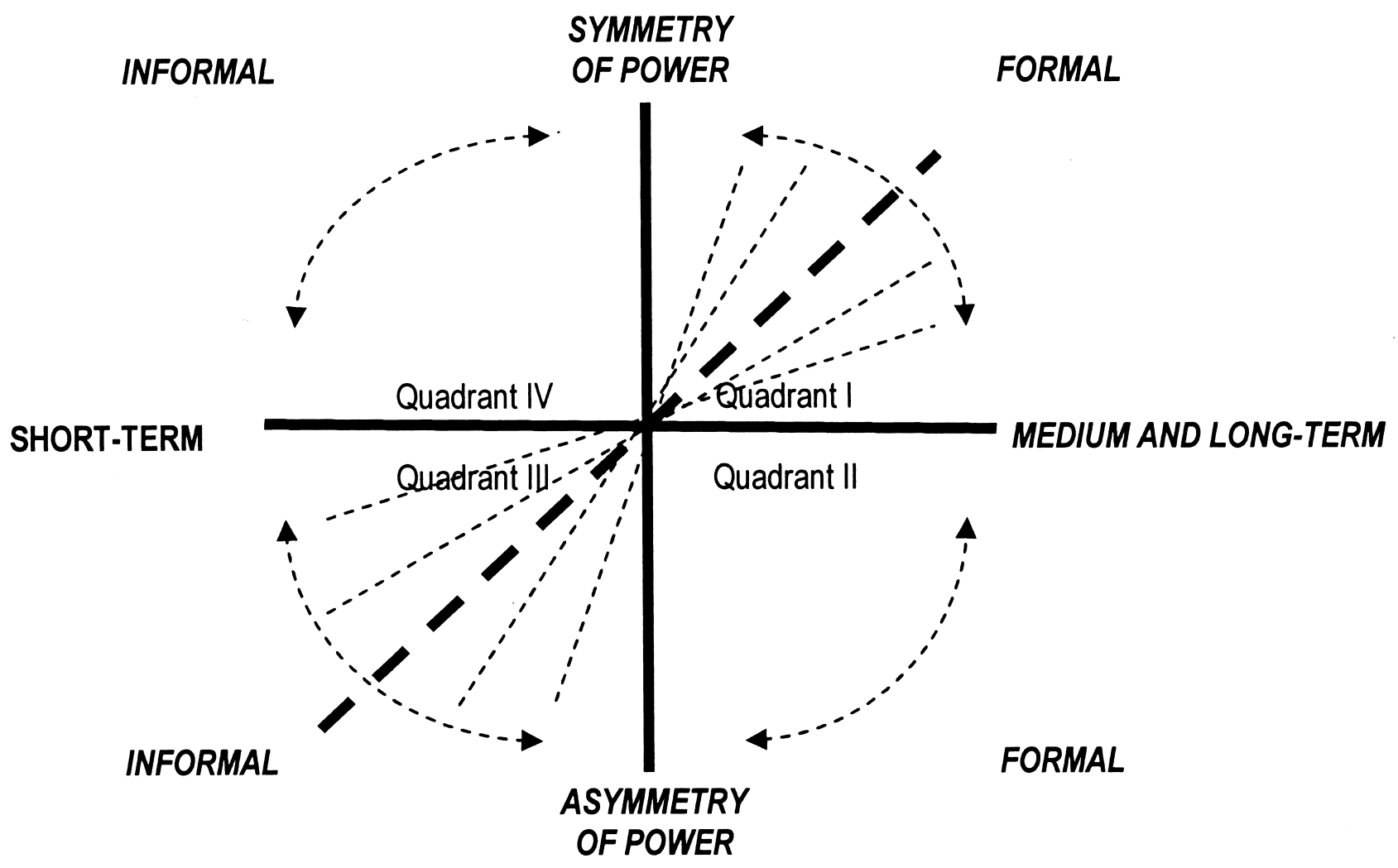

Figure 1. Alternatives for mediation. 
between the parties involved, with different variations across a continuum from greater to lesser symmetry, and the foreseeable temporal perspective in the relationship between the parties, an element that cannot be established absolutely but at least can be predicted to a certain degree as, for example, in the case of a conflict between a teacher and a student in the last year of his degree, or in the case of a conflict between members of the faculty staff and the support staff with stable and consolidated posts. According to Wiseman and Poitras (2002), the guiding principle is to ground the mediation context within the organizational reality -namely, in this case, the hierarchy of power-, as well as to consider social and contextual constraints in the preference for modalities of mediation (LaTour et al., 1976). Also, it is necessary to remember that the ombudspersons/mediators have relative freedom to structure the forms this disputeresolution mechanism takes (Kolb, 1987).

Consequently, the alternatives of mediation proposed are summed up as follows:

The use of a greater number of formal elements of mediation will be more effective when the symmetry of power between the parties is greater and when there is a medium and long-term perspective in their relationship (quadrant I).

Research on the effects of power in the preferences for dispute resolution procedures found that formal procedures, arbitration and advisory arbitration were most preferred when the conflict involved parties of equal power (Arnold \& Carnevale, 1997). Based in these outcomes, the contingent model postulates that when between parties exists symmetry of power, the mediation will be more formal.

In university contexts, an example of this situation might be the following: a conflict between two professors in the same corps (full professors or tenured professors) belonging to the same department or between two support staff members of the same or very similar category working in the same service, and whose seniority in the corps or in the institution is also very similar. These are cases in which there is symmetry or balance of power and in which a long-term temporal relationship is foreseeable (although not inevitable; a change of department or subject area or a transfer to another service or center can always be requested). In these cases, the model postulates (if we are not dealing with, obviously, the infringement of rights or rules) the possible use by the ombudsperson of a formal mediation strategy obviously voluntarily accepted by the parties involved. The objectives of the mediation process aim towards the (re)establishment or improvement of communication and the relationship, as well as an agreement. However, we suggest that, in this case, the effectiveness of the result of the process must be valued to a greater extent due to the ability of the parties to solve for themselves future conflicts or problems -whose occurrence is foreseeable in university contexts characterized, as pointed out above (see Harrison \& Morrill, 2004), by a scarcity of resources, competitiveness, diversity of interests, objectives or values, struggles for power or differences in expectations, among other factors-, without having to appeal again to the University Ombudsperson or to third parties in adversarial or inquisitorial processes (according to the classic distinction proposed by Thibaut and Walker, 1975).

The greater use of informal elements of mediation will be more effective when the asymmetry between the parties is greater and when there is a short-term perspective in their relationship (quadrant III).

When power is unequally distributed, mediation is challenging, and the chances of reaching a mediated settlement are slim (Wiseman \& Poitras, 2002). In this situation, high-powers holders have little interest in the needs of low-power holders; and also high-powers holders are not generally willing to accommodate, and are not likely to initiate a win-win solution (Coleman, 2006; Yarn, 1999). According to Harrison and Morrill (2004), in conflicts where there are limited social ties or little need for a continuing relationship, mediators should avoid attempts at reconciling the relationship. Instead, the focus should be on process that will calm disputant emotions and strains. In conflicts with thus type of social context, mediation features should focus on fact-finding and investigation, keeping parties separate, and searching for a fair outcome. Some examples of this type of situations are as follows: a conflict between a full professor and an undergraduate student because of an incident in class or during an exam, or between the director of a service and a scholarship-holder or collaborator in support or administrative duties. In this example, the relationship between the parties is characterized by a great asymmetry of power and because they are relatively limited in time (a few months or an academic year, at the most, since either of the parties may end the relationship with relative ease). If it is not a case of breaking rules or an infringement of rights, the conflict or the disagreement may be tackled by the University Ombudsperson using a strategy of informal mediation centred on the search for a solution or agreement to resolve the isolated conflict, but without excluding the possibility of improving the relationship between the parties.

Although the balance of power between the parties tends to be asymmetric, to the extent that the possibility of a medium and long-term relationship increases, it will be more effective to increase the formal elements of the mediation process combined with other informal elements (quadrant II).

Harrison and Morrill (2004) argue that if there is a great power difference and a need for continuing the relationship, or even multiplex social ties, then attempting to resolve the dispute in such a formal way that the identity or feelings of the parties are protected, and so prevent conflict escalation. However, if that is not possible because the conflict has escalated, then the mediator should use strategies to deescalate the conflict (i. e., informal tools) before attempting any sort of face-to-face mediation formal sessions. The expected future interactions between the parts can make recommendable the use of more formal elements in the mediation processes (Arnold \& Carnevale, 1997). We may be in the face of 
situations such as a conflict between the head of a department or a full professor with seniority (high power-holder) and a teacher (low power-holder), who has just found a stable position in the department, or a conflict or disagreement between the director of a $\mathrm{PhD}$ thesis and the $\mathrm{PhD}$ student at the beginning of their relationship. Although there is an obvious imbalance of power, the fact that they will -foreseeably- have a long relationship suggests the need to introduce formal elements, together with informal ones, in the mediation so that the parties become conscious of the process and of the need to solve their problems -current and future- and learn to communicate with and relate to each other effectively thereafter (Volpe \& Chandler, 2001). The preservation of working relationships and effective interactions must be an important objective of any organizational complaint mechanism. Ombudsperson work quietly and in a more or less informal way and, in so doing, try to restore and maintain harmony in the university system (Kolb, 1987).

Although the balance of power between the parties tends to be symmetric, to the extent that the relationship is perceived to be limited to a short-term temporal perspective, it will be more effective to increase the informal elements in the mediation process along with formal ones (quadrant IV).

In general, when the relationship is perceived to be a short-term one, or expected future interaction between the disputants is low, it is less probable that the parties will become involved in a formal process of conflict resolution, and even less so when both parties perceive that they have a very similar position of power (Arnold \& Carnevale, 1997). Like Harrison and Morrill (2004) argue, when where there are little need for a continuing relationship, mediators should search for a fair and just outcome; additionally, included a design feature that fosters perspective taking of both sides may help to change the mental models of those involved in conflict. An example of this type of situation is the case of a conflict between two tenured professors belonging to the same corps or two members of the support staff with the same category, but where one of the two is on leave of absence. Just as in the previous assumptions, if the conditions allow for the use of mediation rather than other procedures or petitions of penalization of conflict resolution, the University Ombudsperson may use a mediation strategy that includes more informal elements, along with formal ones that characterize, in general, the conflicts between agents where a balance of power exists.

These examples, although they simplify possible real situations and the multiple factors that may arise in each case, can illustrate the practical use of the proposed contingent model. The aim is not, as already pointed out, a normative model, since the "quantification" of the dimensions considered must be carried out in an approximate way. In any case, what should be highlighted is the need to evaluate, as mentioned in the introduction, the possible influence of the characteristics and aforementioned factors on the effectiveness of the process and the outcomes of the mediation.
Conclusions

Mediation as a strategy to resolve conflicts in university contexts and carried out by the University Ombudsperson can increase its effectiveness if we take into consideration the elements briefly analyzed in this paper which include the most outstanding characteristics of the university structure and 'processes. In this way, we seek to increase the benefits and advantages demonstrated by mediation as compared to adversarial processes of confrontation -as in formal adjudication or courts of justice (Ambrož, 2005; Butts, Munduate, Barón, \& Medina, 2005; Shestowsky, 2004). One of these most outstanding benefits, from the psychosocial perspective which is adopted here, is to provide the foundation for the parties involved to feel as if they are the protagonists of the process as well as the results obtained, thus increasing their level of participation in the processes of decision making leading to agreements and increasing their level of empowerment. Mediation in academia is a viable process for resolving conflict. It preserves the concept of academic freedom and autonomy and allows for faculty empowerment in a constructive, growth-producing process for the institution (Doelker, 1989). Like Coleman (2006) argues, cooperative conflicts, for instance, actually generate power on the parties involved, understood as «power with». It has been confirmed that, in general, mediation gives rise to high levels of satisfaction in its participants, as well as the increasing social value as to its reliability and effectiveness in dispute resolution (Pruitt \& Carnevale, 2003).

The contingent model of mediation presented in this paper leaves from the principle that social and environmental constraints (i. e., power relations between the parties involved and temporal scope of its relationships) can strongly affect both the desirability and effectiveness of different modes of mediation, and these factors should be considered before a given mediation or conflict resolution procedure is employed (Houlden, LaTour, Walker, \& Thibaut, 1976; LaTour et al., 1976). So, this contingent model of mediation can have a doubtless practical value and implications, since it considers the complexity of the university contexts and the adaptation of the type of mediation (formal-informal continuum) to the specific characteristics of each one of the conflicts and the implied parties. Like Lim and Carnevale noted (1990), most of the factors perceived to be contingently effective were more effective as the level of dispute problems increased.

The flexibility and linkage to each context of the elements that characterize the mediation processes, as set out in this paper, is a true social demand today. Like Harrison and Morrill (2004) emphasize, "altering some of the typical design features of the mediation process may also be conducive to greater utilization and success if mediation were to occur in these contexts" (p. 339); and the authors add: "analysis from pragmatic and social contextual approaches to disputing provides a mechanism for understanding the problems encountered by the [university] 
ombudsperson and provides a tool for designing more effective dispute resolution systems" (pp. 318).

Evidently, this does not mean that mediation should replace other mechanisms used for dispute resolution or that it should be used for all types of problems. Rather, after a detailed analysis of the type of conflict, characteristics of the parties involved, balance of power between them, and knowledge of the history of the conflict and the temporal perspective of the relationship between them, it will be necessary to make a decision concerning the possible effectiveness and the level of formality that the mediation process should present. As indigenous conflict resolvers, University Ombudspersons bring distinctive knowledge and skills to university-based conflict situations (Volpe \& Chandler, 2001). It is necessary to recall that the University Ombudsperson who acts as a mediator must possess an adequate preparation and repertory of specific characteristics and skills that guarantee his suitability (Herrman, Hollett, Gale, \& Foster, 2001). Likewise, it is understood that he is perfectly acquainted with the specificities of the university context and the normal relationships established within it, as well as, eventually, the characteristics of the parties in conflict and of the specific problem.

The promotion of a mediation culture, that is, values and beliefs that allow the parties to be responsible, with capacity to face up to and resolve their conflicts, disagreements and complaints, may prove to be an extremely effective mechanism to increase the quality of human relationships, respect and harmony in university contexts, at the same time that potential opportunities that conflicts may mean for change, progress and institutional improvement are taken advantage of (Albert \& Howard, 1985; Doelker, 1989). As Moore affirmed (1994), when he attempted to answer the question, "Why do we mediate?", the majority believe that the community in which we live or the organization in which we work "could be better", and to solve the problems or conflicts that impede this, mediation is preferable to lawsuits, since it is more probable that the former is capable of, in addition to reaching an agreement, maintaining relationships.

In university contexts, characterized by a valuable pluralism and members diversity (of interests, values, experiences, objectives, expectations, opportunities, etc.) and where the temporal perspective of the relationship is usually medium and long-term, it may prove extremely important to transmit and teach its members the unquestionable advantages of mediation, at the same time that there is an increase in the capacity to avoid the «judicialization» of -or the abuse of formal adjudication in- the university life, and to resolve conflicts for themselves. If higher education constituencies to embrace the teaching and the practice of mediation, they can make significant contributions to colleges and universities -and society also gains from a citizenry educated to understand the nature and resolution of conflict (Crohn, 1985). As Shubert and Folger (1983) confirmed in one of the first studies on conflict resolution in institutions of higher education, the use of mediation was more frequent in those that, due to tradition or internal preferences, valued more highly the desire to keep dispute resolution informal, shared the belief that members of the academic community would work together to solve problems, and a need to preserve collegial relationships, among other reasons. In addition, the literature suggests that mediation is most successful when the parties have some form of prior or ongoing relationship (Albert \& Howard, 1985).

In this sense, perhaps the greatest success of the University Ombudsperson as a mediator (and in general, any mediating figure) is when the protagonists that have participated in the process do not need to appeal to him again in the future, not because new conflicts or disagreements do not arise, something which will foreseeably occur, but rather because they have experienced their capacity and responsibility for facing up to and solving their problems effectively and because their relationship allows them to do so.

On the other hand, like Shestowsky (2004) notes, the perceived legitimacy of the university norm system can be enhanced by offering dispute resolution procedures that university members find attractive, and enhance members' perceptions of ex ante procedural fairness by offering procedures that match people's preferences.

This contingent mediation model useful for University Ombudsmen in mediation processes in university contexts presented in this paper has several limitations. It aims to consider the most specific characteristics in university conflicts setting and the level of formalization of mediation process, balance of power, and temporal perspective of the relationship; they are the three dimensions that articulate intervention strategies, and which should be put into practice in order to empirically validate the model, as well as to reformulate and refine its propositions and thus increase its possible effectiveness. It can be interesting in future refinement or research about this contingent model to include the effects of factors like the degree of interdependence or the previous relations between the parties in conflict. Research that relies on contingent mediation interventions, accompanied by measures of mediator behavior and outcomes, is essential if we are to develop a beeper understanding about what is and is not effective in resolving disputes in university contexts. Combined with good research protocols, more systematic research can build on the exploratory thoughts presented here and contribute to the body conflict resolution literature (Volpe \& Chandler, 2001). Additionally, there is a need to better understand the vast untapped area of similarities and differences between University Ombudspersons and the many others indigenous conflict resolvers operating in a variety of non-academic settings.

On the other hand, it is possible that each institution of higher education haves different social and cultural contexts; and inside of each university it is even possible that cultural differences exist, thus like very different social contexts. Future researchers and practitioners should continue to identify and analyze key strategies of mediation and dispute resolution 
systems, their intended and unintended consequences, their functional and dysfunctional outcomes, and the cultural and social contexts where they operate most effectively.

Other limitation of the model are in their potential use in non-ombuds mediation processes or their possible application in other non-academic contexts; studying and comparing other mediation processes in universities, and studying mediation processes in other organizations, corporations or government settings more systematically would allow for generalization beyond the practice of the university ombudspersons. Additionally, it is necessary to include the consideration of the influence of cultural factors (organizational and/or local and national culture). Research that relies on cross contexts and cross cultural components is also essential if we want to develop a better understanding about the contingent mediation model effectiveness and generalization. Like Conlon, Meyer, Lytle, and Willaby (2007) have demonstrated recently, there is not «one best choice» for third party procedures universal to the myriad cultural contexts on our planet. So, further research that relies on cross contexts and cross cultural components is also essential if we want to develop a better understanding about the contingent mediation model effectiveness and generalization in other contexts.

The proposal of this model may be framed within what Donald Schön (e.g., 1983, 1987) called reflective practitioner, that is, reflection on the understandings already built into the skillful actions of everyday practice, and which in the field of mediation has already been very successfully used (e.g., Kolb \& Associates, 1994). As Kressel (1997) pointed out, "the reflective paradigm is designed to produce findings that are directly useful to the practice, compared to the more abstract formulas in which traditional findings are couched" (p. 155). Kressel notes that the skilled mediator is typically relegated to the research sidelines as a passive spectator and «consumer» of research findings. And Kressel adds that practice-oriented reflective mediation research will also need own insights, ideas and models that they help to build a truly self-conscious reflective research paradigm.

In addition, this paper is attributed to a pracademic, as defined by Volpe and Chandler (2001, p. 246): "academics who are scholars and teachers in the field of dispute resolution and actually practice what they preach in their university". Kressel (1997) considers that "the contributions of practitionerscholars are especially likely to be helpful in emerging domains of mediation, such as higher education” (p. 156). The author of this paper is a scholar and teacher of Social Psychology, specializing in the field of Organizational Behavior, and quite familiar with the conflict analysis and dispute resolution methods in organizations. He is also currently and during the last six years University Ombudsman at the Rey Juan Carlos University (Madrid, Spain), a public institution. This paper is the result of the reflection as an academic on, and the experience as, a practitioner in mediation processes as a technique to resolve disputes in university contexts; and anchored in previous theory and research on dispute resolution and mediation in higher education contexts. However, the author does not overlook Gadlin's (2002) opinion: "while there is value in shaping new directions for theory building around the insights and techniques of practitioners, the lopsided venture suffers form several problems" (p. 328), nor when he affirms: "I believe that the relation between theory and practice is always problematic, and would argue that this is a good thing” (p. 327), since both pursue different objectives and reflect different positions in the world. But Rooney (2007) indicates "that you can only really know what has happened in an event after you truly experience it" (p. 244). The contingent model proposed in this paper, though with limitations and the need to be put into practice beyond the experience and practice of he who has formulated it, as well as of empirical verification in different samples and different university contexts, simply aims to slightly alleviate the tension between theory and practice, and modestly contribute to broaden the cycle between these core elements: theory (academic position) $\rightarrow$ practice (mediator as university ombudsperson) $\rightarrow$ theory (practice-based).

\section{References}

Albert, R., \& Howard, D.A. (1985). Informal dispute resolution through mediation. Mediation Quarterly, 10, 99-108.

Alcover, C. Ma (2007). Encuesta sobre el uso de la mediación entre los Defensores Universitarios españoles de universidades públicas $y$ privadas. [Survey on the use of mediation by the University Ombudsman in public and private Spanish universities]. Madrid: Universidad Rey Juan Carlos , unpublished document.

Ambrož, M. (2005). The mediating role of the Ombudsman in the protection of human rights. International Journal of Social Welfare, 14, 145-153.

Balachandra, L., Barrett, F., Bellman, H., Fisher, C., \& Susskind, L. (2005). Improvisation and mediation: balancing acts. Negotiation Journal, 21, 425-434.

Barsky, A.E. (2002). Structural sources of conflict in a university context. Conflict Resolution Quarterly, 20, 161-176.

Bauer, F. (2000). The practice of one Ombudsman. Negotiation Journal, 16, 59-79.

Bing, R., \& Dye, L. (1992). The danger of hierarchical decision making: How a model 'effective' college president alienated and embittered a campus. Academe, 78, 16-19.

Bloland, P.A., \& Nowak, D.B. (1968). The Ombudsman: An Informal Survey of the Implementation of the Ombudsman Concept. Los Angeles: University of Southern California (http://www.crinfo.org/action/search-profile.jsp?key= 2848\&type=print; access: 07/12/22).

Bush, R.B., \& Folger, J.P. (1994). The Promise of Mediation. San Francisco: Jossey-Bass.

Butts, T., Munduate, L., Barón, M., \& Medina, F.J. (2005). Intervenciones de mediación. In L. Munduate, \& F.J. Medina (Eds.), Gestión del conflicto, negociación y mediación (pp. 265-303). Madrid: Pirámide. 
Carnevale, P.J.D. (1992). The usefulness of mediation theory. Negotiation Journal, 8, 837-890.

Chan, H.A. (2005). The Mediator as Human Being. Lima, Ohio: Wyndham Hall Press.

Coleman, T. (2006). Power and conflict. In M. Deutsch, T. Coleman \& E.C. Marcus (Eds.), The Handbook of Conflict Resolution: Theory and Practice (2 ${ }^{\text {nd }}$ ed., pp. 120-143). San Francisco: Jossey-Bass.

Conlon, D.E., Meyer, C.J., Lytle, A.L., \& Willaby, H. W. (2007). Third party interventions across cultures: No "one best choice". Research in Personnel and Human Resources Management, 26, 309-349.

Crohn, M. (1985). Dispute resolution and higher education. Negotiation Journal, 1, 301-305.

Doelker, R.E. (1989). Mediation in Academia: Practicing what we preach. Mediation Quarterly, 7, 157-160.

Espada, L. (2004). El Defensor de la institución universitaria. Vigo: Consello Social, Universidad de Vigo.

Folberg, J. (1983). A mediation overview: History and dimensions of practice. Mediation Quarterly, 1, 3-13.

Folger, J.P., \& Jones, T.S. (1994). New Directions in Mediation. Communication Research and Perspectives. Thousand Oaks: Sage.

Freitag, M. (1995). Le Naufrage de l'université - Et autres essais d'épistémologie politique. Québec: Nuit Blanche, éditeur.

Gadlin, H. (2002). Framing new directions for theory from the experience of practitioners. Negotiation Journal, 18, 327-330.

Gibson, J. (1995). Can't we settle this? Student conflicts in higher education and options for resolution. New Directions for Higher Education, 23, 27-34.

Guerra, N.S., \& Elliott, G. (1996). Ombudsing in an educational institution: Use of implicit and explicit power. (http://www.ombuds.uci.edu/ JOURNALS/1996/ombudsing.html, access: 07/12/13).

Guerra, N.S. \& Flinchbaugh, N. (1993). Expanding the Ombuds Office: A systems approach to dispute resolution on campus. UCI Ombudsman: The Journal 1993 (http://www.ombuds.uci.edu/ JOURNALS/1993/expanding.html, access: 07/12/13).

Gutiérrez, M., \& Martorell, M. (2007). Los Defensores Universitarios. Panorama Social, 6, 59-65.

Harrison, T.R. (2004). What is success in ombuds processes? Evaluation of a University Ombudsman. Conflict Resolution Quarterly, 2004, 21, 313-335.

Harrison, T.R. (2007). My professor is so unfair: Student attitudes and experiences of conflict with faculty. Conflict Resolution Quarterly, 24, 349-368.

Harrison, T.R. \& Morrill, C. (2004). Ombuds processes and disputant reconciliation. Journal of Applied Communication Research, 32, 318-335.

Hartman, J.B. (1977). Change and conflict in the University. Journal of Educational Thought, 11, 3-15.

Herrman, M.S., Hollett, N., Gale, J., \& Foster, M. (2001). Defining mediator knowledge and skills. Negotiation Journal, 17, 139-153.

Hirschman, A.O. (1970). Exit, Voice, and Loyalty. Responses to Decline in Firms, Organizations, and States. Cambridge: Harvard University Press.
Holaday, L.C. (2002). Stage development theory: A natural framework for understanding the mediation process. Negotiation Journal, 18, 191-210.

Holton, S.A. (1995). And now... the answers! How to deal with conflict in higher education. New Directions for Higher Education, 23, 79-89.

Holton, S.A. (Ed.) (1998). Mending the Cracks in the Ivory Tower: Strategies for Conflict Management in Higher Education. Boston: Anker.

Holton, S.A., \& Phillips, G. (1995). Can't live with them, can't live without them: Faculty and administrators in conflict. New Directions for Higher Education, 23, 43-50.

Holton, S.A., \& Warters, W. (1995). Conflict management programs in the United States and Canada. New Directions for Higher Education, 23, 97-124.

Houlden, P., LaTour, S., Walker, L., \& Thibaut, J. (1976). Preference for modes of dispute resolution as a function of process and decision control. Journal of Experimental Social Psychology, 14, 13-30.

Kolb, D.M. (1987). Corporate ombudsman and organization conflict resolution. Journal of Conflict Resolution, 31, 673-691.

Kolb, D.M., \& Associates (1994). When Talk Works: Profiles of Mediators. San Francisco: Jossey-Bass.

Kressel, K. (1997). Practice-relevant research in mediation: Toward a reflective research paradigm. Negotiation Journal, 13, 143-160.

Kressel, K. (2006). Mediation revisited. In M. Deutsch, P.T. Coleman \& E.C. Marcus (Eds.), The Handbook of Conflict Resolution: Theory and Practice (2 ${ }^{\text {nd }}$ ed., pp. 726-756). Hoboken: Wiley.

Kressel, K., \& Pruitt, D.G. (1989). A research perspective on the mediation of social conflict, In K. Kressel, \& D.G. Pruitt (Eds.), Mediation Research: The Processes and Effectiveness of Third Party Intervention (pp. 394-435). San Francisco: Jossey Bass.

LaTour, S., Houlden, P., Walker, L., \& Thibaut, J. (1976). Some determinants of preference for modes of conflict resolution. Journal of Conflict Resolution, 20, 319-356.

Lewicki, R.J., Weiss, S.E., \& Lewin, D. (1992). Models of conflict, negotiation and third party intervention: A review and synthesis. Journal of Organizational Behavior, 13, 209-252.

Lim, R.G., \& Carnevale, P.J.D. (1990). Contingencies in the mediation of disputes. Journal of Personality and Social Psychology, 58, 259-272.

Mankin, L.D. (1996). The role of the Ombudsman in Higher Education. Dispute Resolution Journal, Oct., 46-49.

Menkel-Maedow, C. (1995). The many ways of mediation: The transformations of traditions, ideologies, paradigms, and practices. Negotiation Journal 11, 217-242.

Miklas, E.J., \& Kleiner, B.H. (2003). New developments concerning academic grievances. Management Research News, 26, 141-147.

Moore, C.M. (1994). Why we do mediate? In J.P. Folger, \& T.S. Jones (Eds.), New Directions in Mediation. Communication Research and Perspectives (pp. 265-275). Thousand Oaks: Sage.

Munduate, L., Ganaza, J., Peiró, J.Mª., \& Euwema, M.C. (1999). Patterns of styles in conflict management and effectiveness. The International Journal of Conflict Management, 10, 5-24. 
Ostar, A.W. (1995). Institutional conflict. Conflict Management in Higher Education, 92, 59-62.

Pérez, J., Sánchez, T., \& Vila, J. (2004). Los Defensores Universitarios y el reto de la calidad. Madrid: Dykinson.

Perinat, A. (2004). Conocimiento y educación superior. Nuevos horizontes para la universidad del siglo XXI. Barcelona: Paidós.

Picard, C.A. (2004). Exploring and integrative framework for understanding mediation. Conflict Resolution Quarterly, 21, 295-311.

Pruitt, D.G., \& Carnevale, P.J.D. (2003). Negotiation in Social Conflict ( $2^{\text {nd }}$ ed.). Pacific Grove: Brooks/Cole.

Rahim. M.A. (2001). Managing Conflict in Organizations (3 ${ }^{\text {nd }}$ ed.). Wesport: Quorum Books.

Raven, B.H. (1992). A power/interaction model of interpersonal influence: French and Raven thirty years later. Journal of Social Behavior and Personality, 7, 217-244.

Raven, B.H., Schwarzwald, J., \& Koslowsky, M. (1998). Conceptualizing and measuring a power/interaction model of interpersonal influence. Journal of Applied Social Psychology, 28, 307-332.

Robbins, L.P., \& Deane, W.D. (1986). The corporate ombuds: A new approach to conflict management. Negotiation Journal, 2, 195-205.

Rooney, G. (2007). The use of intuition in mediation. Conflict Resolution Quarterly, 25, 239-253.

Ross, O. (2003). Situational Mediation: Sensible Conflict Resolution. Ravensdale: Issue Press.

Rowe, M.P. (1987). The Corporate Ombudsman: An Overview and analysis. Negotiation Journal, 3, 127-140.

Rowe, M.P. (1991). The Ombudsman's role in a dispute resolution system. Negotiation Journal, 7, 353-362.

Rowe, M.P. (1995). Options, functions, and skills: What an organizational ombudsman might want to know. Negotiation Journal, 11, 103-114.

Rubin, J.Z. (1980). Experimental research on third-party intervention in conflict: Toward some generalizations. Psychological Bulletin, 87, 379-391.

Schön, D.A. (1983). The Reflective Practitioner. New York: Basic Books.

Schön, D.A. (1987). Educating the Reflective Practitioner. San Francisco: Jossey-Bass.

Serrano, G. y Méndez, G. (1999). Las intervenciones de los mediadores. Revista de Psicología General y Aplicada, 52, 235-253.

Shapiro, D.L., \& Kolb, D.M. (1994). Reducing the litigious mentality by increasing employees' desire to communicate grievances. In S.B. Sitkin, \& R.J. Bies (Eds.). The Legalistic Organization (pp. 304-326). Thousand Oaks: Sage.

Shelton, R.L. (2000). The institutional ombudsman: A university case study. Negotiation Journal, 16, 81-98.

Shestowsky, D. (2004). Procedural preferences in alternative dispute resolution. A closer, modern look at an old idea. Psychology, Public Policy, and Law, 3, 211-249.
Shubert, J.J., \& Folger, J.P. (1986). Learning from Higher Education. Negotiation Journal, 2, 395-406.

Stieber, C. (1982). Resolving campus disputes: Notes of a University Ombudsman. Arbitration Journal, 37, 6-11.

Stieber, C. (1991). Reflections: Seventeen years as MSU Ombudsman. MSU Alumni Magazine, Fall, 28-30.

Stieber, C. (2000). 57 varieties: Has the Ombudsman concept become diluted? Negotiation Journal, 16, 49-57.

Thibaut, J. \& Walker, L. (1975). Procedural Justice: A Psychological Analysis. Hillsdale: Lawrence Erlbaum.

Van de Vliert, E., Euwema, M.C., \& Huismans, S.E. (1995). Managing conflict with a subordinate or a superior: Effectiveness of conglomerated behavior. Journal of Applied Psychology, 80, 271-281.

Vice, J.W. (1994). University ombuds roles. Expanding the Ombuds Office: A systems approach to dispute resolution on campus. UCI Ombudsman: The Journal 1994 (http:// www.ombuds. uci.edu/ JOURNALS/1994/ombuds_role.html, access: 07/12/20).

Volpe, M.R., \& Chandler, D. (2001). Resolving and managing conflicts in academia communities: The emerging role of the "pracademic", Negotiation Journal, 17, 245-255.

Volpe, M.R., \& Witherspoon, R. (1992). Mediation and cultural diversity on college campuses. Mediation Querterly, 9, 341-351.

Wall, J.A. (1981). Mediation: An analysis, review, and proposed research. Journal of Conflict Resolution, 25, 157-180.

Wall, J.A., \& Callister, R.R. (1995). Conflict and its management. Journal of Management, 21, 515-558.

Wall, J.A., Stark, J.B., \& Standifer, R.L. (2001). Mediation. A current review and theory development. Journal of Conflict Resolution, 45, 370-391.

Wallace, G. (1993). Recent role variations in the ombudsman in education. UCI Ombudsman: The Journal 1993 (http://www. ombuds.uci.edu/JOURNALS/1993/variations.html, access: 07/11/16).

Warters, W.C. (1995). Conflict management in higher education: A review of current approaches. New Directions for Higher Education, 92, 71-78.

Warters, W.C. (2000). Mediation in the Campus Community: Designing and Managing Effective Programs. San Francisco: Jossey-Bass.

Winslade, J., \& Monk, G. (2000). Narrative Mediation: A New Approach to Conflict Resolution. San Francisco: Jossey-Bass.

Wiseman, V., \& Poitras, J. (2002). Mediation within a hierarchical structure: How can it be done successfully? Conflict Resolution Quarterly, 20, 51-65.

Yarn, D.H. (Ed.) (1999). Dictionary of Conflict Resolution. San Francisco: Jossey-Bass.

Received January 31, 2008 Revision received July 16, 2008 Accepted September 16, 2008 